\title{
The effect of rapid response teams on end-of-life care: A retrospective chart review
}

\author{
Benjamin Tam MDํㅡㄹ
}

B Tam, M Salib, A Fox-Robichaud. The effect of rapid response teams on end-of-life care: A retrospective chart review. Can Respir J 2014;21(5):302-306.

BACKGROUND: A subset of critically ill patients have end-of-life (EOL) goals that are unclear. Rapid response teams (RRTs) may aid in the identification of these patients and the delivery of their EOL care.

OBJECTIVES: To characterize the impact of RRT discussion on EOL care, and to examine how a preprinted order (PPO) set for EOL care influenced EOL discussions and outcomes.

METHODS: A single-centre retrospective chart review of all RRT calls (January 2009 to December 2010) was performed. The effect of RRT EOL discussions and the effect of a hospital-wide PPO set on EOL care was examined. Charts were from the Ontario Ministry of Health and LongTerm Care Critical Care Information Systemic database, and were interrogated by two reviewers.

RESULTS: In patients whose EOL status changed following RRT EOL discussion, there were fewer intensive care unit (ICU) transfers $(8.4 \%$ versus $17 \% ; \mathrm{P}<0.001$ ), decreased ICU length of stay (5.8 days versus 20 days; $\mathrm{P}=0.08$ ), increased palliative care consultations (34\% versus $5.3 \%$; $\mathrm{P}<0.001)$ and an increased proportion who died within $24 \mathrm{~h}$ of consultation $(25 \%$ versus $8.3 \% ; \mathrm{P}<0.001)$. More patients experienced a change in EOL status following the introduction of an EOL PPO, from 20\% (before) to $31 \%$ (after) $(\mathrm{P}<0.05)$.

CONCLUSIONS: A change in EOL status following RRT-led EOL discussion was associated with reduced ICU transfers and enhanced access to palliative care services. Further study is required to identify and deconstruct barriers impairing timely and appropriate EOL discussions.

Key Words: Intensive care unit transfer; Palliative care; Physician Ordered Spectrum of Treatment (POST); Preprinted orders

$\mathrm{R}$ apid response teams (RRTs) were designed to assess and treat deteriorating ward patients. The aim of RRTs is to decrease the number of cardiac arrests, intensive care unit (ICU) transfers and inhospital mortality. These goals have been met with variable success in the literature, with some prospective cohort studies reporting reductions in cardiac arrests (1-4). However, these results were not replicated in the large, multicentre, cluster randomized controlled Medical Early Response Intervention and Therapy (MERIT) trial (5). The MERIT trial suggested that there was an association with RRTs and an increase in do-not-resuscitate orders $(6,7)$. Further studies have also documented RRT involvement in end-of-life (EOL) care (8-10).

To support EOL care, our institution implemented a hospital-wide policy and associated preprinted order set known as the PhysicianOrdered Spectrum of Treatment (POST) form. The POST form acted as an extension of a 'do not resuscitate' status. The form engaged health care providers in conversations with patients and families regarding life-sustaining interventions such as cardiopulmonary resuscitation, intubation, defibrillation, ICU transfer, antibiotics, blood products or intravenous lines (11-14). Several studies have

\section{L'effet d'équipes d'intervention rapide sur les soins de fin de vie : l'analyse rétrospective de dossiers}

HISTORIQUE : Un sous-groupe de patients gravement malades a des objectifs de fin de vie (FdV) qui ne sont pas clairs. Des équipes d'intervention rapide (ÉIR) peuvent contribuer à cibler ces patients et à leur donner des soins de FdV.

OBJECTIFS : Caractériser les répercussions des conversations avec une ÉIR sur les soins de FdV et examiner l'influence d'un protocole préimprimé (PPI) sur les soins de FdV sur les conversations et les résultats relatifs à la FdV.

MÉTHODOLOGIE : Les chercheurs ont procédé à une analyse rétrospective des dossiers d'un centre sur tous les appels d'ÉIR (de janvier 2009 à décembre 2010). Ils ont examiné l'effet des conversations avec l'ÉIR sur la FdV et celui d'un PPI panhospitalier sur les soins de FdV. Les dossiers, fouillés par deux analystes, provenaient de la base de données du Système d'information sur les soins aux malades en phase critique du ministère de la Santé et des Soins de longue durée de l'Ontario.

RÉSULTATS : Chez les patients dont la situation de FdV a changé après des conversations avec l'ÉIR sur la FdV, on constatait moins de transferts à l'unité de soins intensifs (USI, 8,4 \% au lieu de $17 \%$; $\mathrm{P}<0,001$ ), une hospitalisation moins longue à l'USI ( 5,8 jours au lieu de $20 ; \mathrm{P}=0,08)$, plus de consultations en soins palliatifs ( $34 \%$ au lieu de $5,3 \%$; $\mathrm{P}<0,001$ ) et une plus grande proportion de décès dans les 24 heures suivant la consultation ( $25 \%$ au lieu de $8,3 \% ; \mathrm{P}<0,001$ ). Plus de patients ont présenté un changement de leur situation de FdV après l'adoption d'un PPI de FdV, passant de $20 \%$ (avant) à $31 \%$ (après) $(\mathrm{P}<0,05)$.

CONCLUSIONS : Un changement à la situation de FdV après des conversations dirigées par l'ÉIR sur la FdV s'associait à une diminution des transferts à l'USI et à un meilleur accès aux services de soins palliatifs. D'autres études s'imposent pour déterminer et éliminer les obstacles nuisant à des conversations opportunes et adaptées sur la FdV.

shown that POST forms ensured that patient treatment preferences were honoured; however, these studies were performed in long-term care settings $(12,13)$. Few studies have examined POST use in the critical care setting; furthermore, these studies were limited by sample size and cointerventions $(15,16)$.

The premise of our study was that hospitalized patients are in fragile condition and, although restorative therapies are often the goal, there are patients who do not want or who would not benefit from aggressive resuscitative measures. As 'first responders' for critically ill ward patients, RRTs have the opportunity to recognize and treat patients who would benefit from EOL care. We sought to characterize the effect of RRT EOL discussions on EOL care. We also characterized the proportion of patients seen by RRTs with EOL care issues. Finally, we examined how the introduction of a hospital-wide EOL preprinted order set influenced EOL discussions and EOL care.

\section{METHODS}

The present study was a single-centre, retrospective chart review conducted at the Hamilton Health Sciences Hamilton General Hospital

${ }^{1}$ Department of Medicine, Division of General Internal Medicine; ${ }^{2}$ Department of Medicine, Division of Critical Care Medicine, McMaster University, Hamilton, Ontario

Correspondence: Dr Alison Fox-Robichaud, Department of Medicine, Division of Critical Care Medicine, McMaster University, DBRI C5-106, 237 Barton Street East, Hamilton, Ontario L8L 2X2. Telephone 905-521-2100 ext 40742, e-mail afoxrob@mcmaster.ca 
(Hamilton, Ontario), a 458-bed tertiary care centre and regional centre of excellence specializing in cardiac and vascular care, neuroscience, trauma and burn treatment, stroke and rehabilitation.

The RRT at the authors' site has been a Ministry of Health and Long-Term Care of Ontario-funded team since 2006 and includes an ICU physician, critical care nurses and registered respiratory therapists. Critical care residents or fellows may support the team on some occasions. Any health care provider with concerns regarding patients' airway, breathing or circulation can activate the team. The nurses and respiratory therapists on the RRT also have several medical directives that allows them to initiate resuscitative therapy before a licensed physician arrives at the bedside. They have also received additional training in EOL discussions.

The POST was implemented in January 2010 as a hospital-wide policy to improve EOL care. Institutional policy dictated that the POST form was to be completed for all hospitalized patients with a predicted life expectancy $<1$ year. Before its implementation, there was a one-month period of distributed education on using the POST form. The POST form was examined because it coincided with the study period and was a confounder that may have effected RRT EOL discussions.

\section{Ethics}

The present study was approved by Hamilton Health Sciences Research Ethics Board (approval number was 11-463-C). The need for informed consent was waived.

\section{Data collection}

The chart review was composed of all patients seen by the RRT team between January 1, 2009 and December 31, 2010. RRT-based EOL discussions were tracked. Data were gathered from the Ontario Ministry of Health and Long-Term Care Critical Care Information Systemic database. Charts were divided into code status discussion initiated, code status discussion revisited, code status previously established and code status discussion not appropriate at the time or for this patient. These distinctions were determined by the RRT's registered nurse or respiratory therapist, who completed the team call record at the time of RRT consultation. Charts coded as 'discussion initiated' and 'discussion revisited' were considered to be positive for EOL discussion. Two reviewers reviewed the charts independently. If the RRT had an EOL discussion, the patient's medical record was reviewed for patient demographics, admitting service, code status at time of consultation, completion of POST form, a change in EOL status following consultation, ICU transfer following consultation, total ICU length of stay (LOS) following transfer, if death occurred within $24 \mathrm{~h}$ following consultation and whether palliative care was involved in EOL care.

\section{Data analysis}

The analysis focused on RRT EOL discussion with critically ill ward patients. To determine the effect of the RRT on EOL care, patients with and without a change in EOL status following RRT EOL discussion were compared. To determine the effect of the POST form on RRT EOL discussions, the outcomes before the introduction of the POST (January 1, 2009 to December 31 2009) and following the introduction of the POST (January 1, 2010 to Decemebr 31, 2010) were compared. Discrete variables were described as proportions and compared using $\chi^{2}$ tests. Continuous variables were reported as mean $\pm \mathrm{SD}$ and compared using unpaired $t$ tests; $\mathrm{P}<0.05$ was considered to be statistically significant.

\section{RESULTS}

\section{Patient population}

Between January 1, 2009 and December 31, 2010, the RRT saw 5320 patients. Of 5320 patients, 1254 (24\%) were seen as a new RRT consultation while 3155 (59\%) were seen in ICU discharge follow-up. The method in which RRT was involved was not documented for

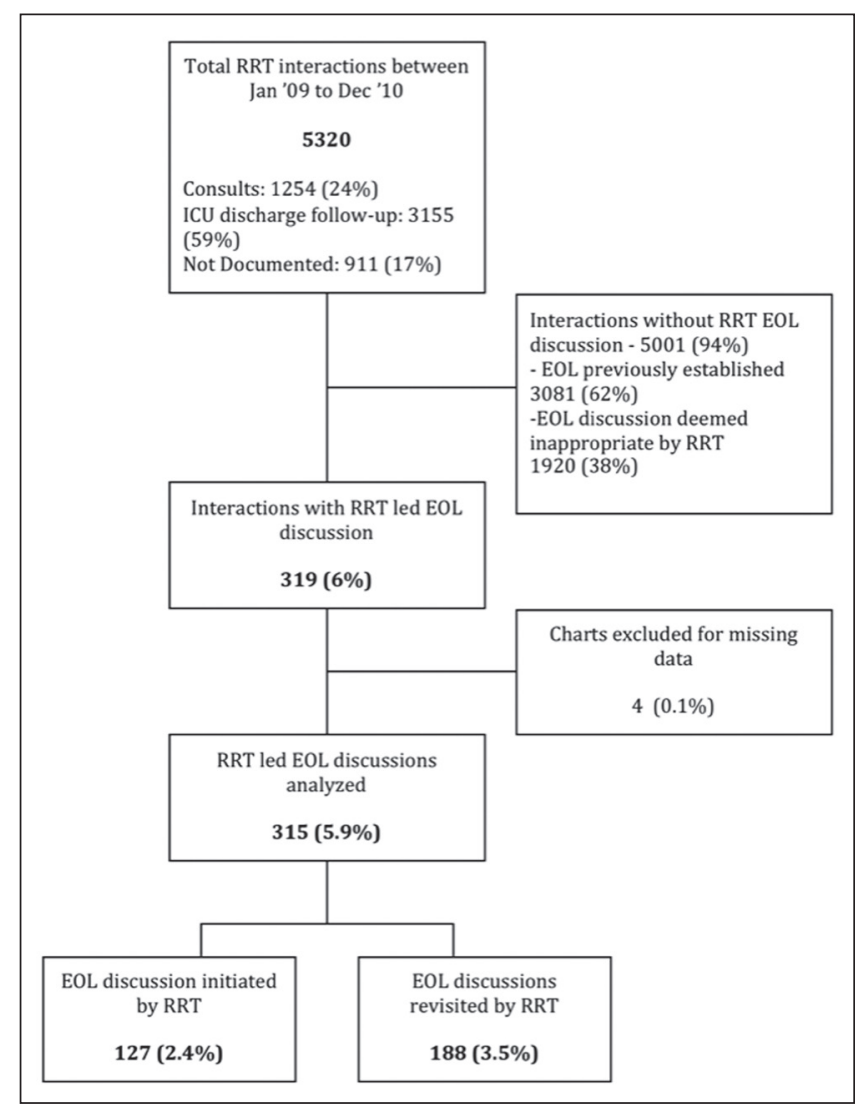

Figure 1) Patient population consort diagram. Dec December; EOL End of life; ICU Intensive care unit; Jan January; RRT Rapid response team

911 patients (17\%). Three hundred nineteen patients (6\%) had their code status discussion initiated or revisited by the RRT; 3081 (58\%) had a previously established code status. A code status discussion was deemed not appropriate for 1920 patients (36\%) (Figure 1).

Effect of RRT EOL discussion on EOL care

Of the patients who RRT initiated or revisited code status, 276 (89\%) were for full resuscitation at the time of consultation. The EOL status was changed in $83(27 \%)$ patients, all of whom were for full resuscitation at the time of consultation. In patients with a change in EOL status, there were fewer ICU transfers ( $8 \%$ versus $16 \%$; $\mathrm{P}<0.01)$, more palliative services arranged ( $34 \%$ versus $5 \% ; \mathrm{P}<0.01)$ and more patients who passed away within 24 h of RRT consultation ( $25 \%$ versus $8 \% ; \mathrm{P}<0.01$ ). There was a trend toward decreased ICU LOS (six days versus 20 days; $\mathrm{P}=0.08$ ) (Table 1 ).

\section{Effect of POST form on EOL care}

There were minimal differences when comparing outcomes before and following POST implementation. There were similar proportions of patients who were for full resuscitation at time of consultation $(89 \%$ before versus $85 \%$ after; $\mathrm{P}=0.72$ ). There was a significant increase in the proportion of patients who had a change in code status following implementation of the POST form (20\% before versus $31 \%$ after; $\mathrm{P}<0.05)$. However, there was no difference in proportion transferred to the ICU ( $13 \%$ before versus $15 \%$ after; $\mathrm{P}=0.55$ ), average ICU LOS ( 12 days before versus 14 days after; $\mathrm{P}=0.38)$, nor was there a difference in proportion with palliative care involved ( $14 \%$ before versus $12 \%$ after; $\mathrm{P}=0.55$ ). There was a trend toward increased proportion of patients who died within $24 \mathrm{~h}$ of RRT consultation ( $8.6 \%$ before versus $16 \%$ after; $\mathrm{P}=0.08$ ) (Table 2 ). 
TABLE 1

\section{Effect of rapid response team (RRT) end-of-life (EOL)} interaction on EOL care

\begin{tabular}{lccc}
\hline & \multicolumn{2}{c}{$\begin{array}{c}\text { Change in EOL status } \\
\text { following RRT discussion }\end{array}$} & \\
\cline { 2 - 3 } & Yes (n=83) & No $(\mathbf{n}=\mathbf{2 3 2})$ & $\mathbf{P}$ \\
\hline Age, years, mean \pm SD & $75 \pm 11$ & $73 \pm 13$ & 0.10 \\
Male sex & 65 & 56 & 0.38 \\
Full code at time of consult & 100 & 83 & 0.21 \\
Completed POST & 23 & 11 & $<0.05$ \\
Transferred to ICU & 8.4 & 16 & $<0.001$ \\
ICU LOS if transferred, days, & $5.8 \pm 4.7$ & $20 \pm 14$ & 0.08 \\
$\quad$ mean \pm SD & & & \\
Palliative care involvement & 34 & 5.3 & $<0.001$ \\
Died within 24 h of RRT consult & 25 & 8.2 & $<0.001$ \\
\hline
\end{tabular}

Data presented as \% unless otherwise indicated. consult Consultation; ICU Intensive care unit; LOS Length of stay; POST Physician-Ordered Spectrum of Treatment form

\section{DISCUSSION}

We found that RRTs influenced EOL care through EOL discussions. In patients who experienced a change in EOL status following RRT EOL discussion, there were fewer ICU transfers, increased palliative services and more patients who died within $24 \mathrm{~h}$. Furthermore, the POST form may be a tool that is associated with more EOL discussions, although it did not impact other EOL outcomes in our critical care setting.

RRT involvement in EOL care is an evolving concept. Vasquez et al (8) found that implementation of the RRT increased formal comfort care orders, administration of opioids and chaplain visits. Smith et al (17) found that the implementation of RRTs increased the trend of do-not-resuscitate orders without impacting hospital mortality. An analysis of RRTs and EOL status from the MERIT study found that approximately $8 \%$ of RRT calls resulted in a change of EOL status (6). Jones et al (18) similarly found that approximately $10.8 \%$ of patients had a new do-not-resuscitate order following RRT involvement. In contrast, we found that only $1.5 \%$ of total RRT visits resulted in a change in EOL status. This difference may have arisen because we included both RRT consultations and ensuing ICU discharge followups in our analysis. Only 24\% of our total patients were RRT consultations. Examining this subgroup only, we found that our results were more comparable with the MERIT study, with $5 \%$ of patients having a change in EOL status following RRT consultation. As such, our figure is a comprehensive report of all RRT discussion in EOL care.

The extent of RRT involvement in EOL care is not yet clear. Downar et al $(9,10)$ found that RRT involvement was not associated with improved access to palliative services, spiritual care and comfort medications. This outcome may be attributed to the study population. Downar et al (10) compared EOL care for patients who had died with versus without RRT consult. Patients referred to the RRT may have had a reversible condition amenable to restorative therapy as opposed to palliation. Conversely, patients who were not referred may have had irreversible conditions more suited to palliative care. This was suggested by the significantly increased proportion of patients with irreversible poor prognostic factors, palliative care consultations and shorter time to withdrawal of life support (10). In contrast, we studied patients who the RRT selected for an EOL discussion at the time of RRT consultation. As such, our study suggests that the RRT was able to identify and treat patients who would benefit from palliative care in the critical care setting.

Although our study showed that RRTs could successfully initiate EOL care in critical care scenarios, this may not by the optimal time to discuss goals of care and resuscitation status. RRT involvement in EOL care suggests that there was room to enhance predeterioration EOL care. Previous studies have shown that clinical deterioration is not a
TABLE 2

Effect of Physician-Ordered Spectrum of Treatment (POST) form on rapid response team (RRT) end-of-life care

\begin{tabular}{lccc}
\hline & \multicolumn{2}{c}{ POST implementation } & \\
\cline { 2 - 3 } & Pre $(\mathbf{n}=\mathbf{1 4 0})$ & Post $(\mathbf{n}=175)$ & $\mathbf{P}$ \\
\hline Age, years, mean \pm SD & $75 \pm 12$ & $73 \pm 13$ & 0.54 \\
Male sex & 58 & 58 & 0.91 \\
Full code at time of consult & 89 & 85 & 0.72 \\
Completed POST & 1.4 & 25 & $<0.001$ \\
Change in code status following & 20 & 31 & $<0.05$ \\
$\quad$ consult & 13 & 15 & 0.55 \\
Transferred to ICU & $12 \pm 16$ & $14 \pm 44$ & 0.38 \\
ICU LOS if transferred, days, & & & \\
$\quad$ mean \pm SD & 14 & 12 & 0.55 \\
Palliative care involvement & 8.6 & 16 & 0.08 \\
Died within 24 h of RRT consult & & & \\
\hline
\end{tabular}

Data presented as \% unless otherwise indicated. consult Consultation; EOL End of life; ICU Intensive care unit; LOS Length of stay

sudden process and that the majority of cases present with antecedent clues such as hypotension or hypoxia (19). Responding to these clinical perturbations is only part of the care process. These fluctuations in clinical status should act as stop points for all health care providers to reassess the goals of care and resuscitation status with the patients and families.

However, EOL care is not well addressed in hospital. Heyland (20) found that $76 \%$ of elderly patients have considered EOL care and only $12 \%$ preferred life-prolonging care. However, only $30 \%$ of medical documentation accurately reflected the patients' wishes. Reasons for not documenting an EOL status could be influenced by the patient and family, the clinician or the institution. Family/patient factors included unrealistic patients and families, inability of patients to participate in discussions and lack of advance directives $(21,22)$. Clinician factors included insufficient training, competing time demands and insufficient remuneration (21-24). Institutional factors included suboptimal space for family meetings and lack of palliative care services $(22,23)$.

Enhancing EOL quality will require multitiered interventions enacted through institutions, clinicians and patient/families. One intervention our institute implemented to support EOL discussions is the POST form. Previous literature suggested that similar forms may be used in a hospice or long-term care setting to effectively ensure adherence to patient wishes in an EOL setting (11-13). However, benefit of the POST form requires further study in critical care settings (15). Curtis et al (25) reported on a palliative care order form on EOL care in the ICU. They found no differences in quality of death or dying for patient families or nurses. They also found no differences in ICU LOS or time to withdrawal of mechanical ventilation. Similarly, we found no changes in ICU transfers, ICU LOS or palliative services before and after POST implementation. We did find that there were more changes to EOL status following the implementation of the POST form. This resulted either because the POST form helped guide more fruitful discussions or because it helped increase documentation.

Enhanced in-hospital EOL care is unlikely to arise from policy changes alone. There is room to improve clinician involvement in EOL care. O'Mahony et al (26) reported successful integration of a palliative care team into an ICU. They found that there was increased opioid use, formalized advanced directives and utilization of hospices, in addition to decreased investigations and nonbeneficial life-prolonging therapies. Furthermore, it is important to consider patient and family factors in a comprehensive plan for improving in-hospital EOL care. Heyland (27) showed that seriously ill patient and family members want trust in their clinicians, avoidance of nonbeneficial life support, symptom relief and a chance to prepare for the EOL (27). As such, establishing effective communication among health care providers, patients and 
families is fundamental. Strategies to improve communication include developing clinician communication skills, establishing regular family meetings and promoting interdisciplinary involvement in EOL care $(16,21-24,28-34)$.

Our study had strengths and limitations. The retrospective design of our study, although useful in hypothesis generation, had inherent limitations. First, although we conducted a comprehensive review of all patients seen by the RRT over two years, we found that only a small proportion had EOL discussions. This may have been the case for several reasons. The decision to initiate an EOL discussion was at the discretion of the RRT member. Several factors could have influenced this decision including the health of patient, the predicted response to resuscitation, previous EOL discussions or the presence of other parties managing the EOL process. As such, there may have been systematic differences that we were not able to detect.

One systematic difference that may have influenced the results of our study was patient illness severity. The change in EOL status following RRT involvement may have been driven by illness severity as opposed to RRT EOL discussions. Due to data limitations, we were unable to determine whether there were any systematic differences in illness severity between patients who had a change in EOL status and those who did not. Even if this was the case, increased illness severity in patients with high unlikelihood of benefiting from resuscitative measures should drive EOL discussions and subsequent EOL care. The present study would then suggest that RRTs had the ability to identify deteriorating patients who benefited from palliation rather than resuscitation. More work is required to determine how accurately RRTs prognosticate patients.

Furthermore, although we selected quantifiable and patientimportant outcomes to review, the scope of our analysis was limited by data restrictions inherent in a retrospective study. We found that $26 \%$ of patients who had an EOL discussion with the RRT had a subsequent

\section{REFERENCES}

1. Jones D, Bellomo R, DeVita MA. Effectiveness of the medical emergency team: The importance of dose. Crit Care 2009;13:313.

2. Tobin AE, Santamaria JD. Medical emergency teams are associated with reduced mortality across a major metropolitan health network after two years service: A retrospective study using government administrative data. Crit Care 2012;16:R210.

3. Guirgis FW, Gerdik C, Wears R, et al. Proactive rounding by the rapid response teams reduces inpatient cardiac arrest. Resuscitation 2013;84:1668-73.

4. Beitler JR, Link N, Bails DB, Hurdle K, Chong DH. Reduction in hospital-wide mortality after implementation of a rapid response team: A long-term cohort study. Crit Care 2011;15:R269.

5. Hillman K, Finfer S, Bellomo R, et al. Introduction of the medical emergency team (MET) system: A cluster-randomised controlled trial. Lancet 2005;365:1-7.

6. Chen J, Flabouris A, Bellomo R, Hillman K, Finfer S. The Medical Emergency Team system and not-for-resuscitation orders: Results from the MERIT study. Resuscitation 2008;79:391-7.

7. Smith GB. Increased do not attempt resuscitation decision making in hospitals with a medical emergency teams system - cause and effect? Resuscitation 2008;79:346-7.

8. Vazquez R, Gheorghe C, Grigoriyan A, et al. Enhanced end-of-life care associated with deploying a rapid response team: A pilot study. J Hosp Med 2009;4:449-52.

9. Downar J, Rodin D, Barua R, et al. Rapid response teams, do not resuscitate orders, and potential opportunities to improve end-oflife care: A multicentre retrospective study. J Crit Care 2013;28:498-503.

10. Downar J, Barua R, Rodin D, et al. Changes in end of life care 5 years after the introduction of a rapid response team: A muticentre retrospective study. Resuscitation 2013;84:1339-44.

11. Bakitas M, Kryworuchko J, Matlock DD, Volandes AE. Palliative medicine and decision science: The critical need for a shared agenda to foster informed patient choice in serious illness. J Palliat Med 2011;14:1109-16.

12. Hickman SE, Nelson CA, Moss AH, et al. Use of the Physician Orders for Life-Sustaining Treatment (POLST) paradigm program in the hospice setting. J Palliat Med 2009;12:133-41. change in EOL status; we do not know whether this number was appropriate. Seventy-four percent of patients who the RRT believed warranted an EOL discussion did not have a subsequent change in EOL status. EOL discussions could have resulted in more than a change in EOL status. Other outcomes that may have been affected include dyspnea management, avoiding unnecessary and invasive therapies, treatment of pain, ascertaining patient and family values, and providing support $(8,31,35)$. As such, the $74 \%$ of patients who did not have a change in EOL status following RRT discussion may have received unmeasured EOL care. Further work is required to delineate the differences between the two groups.

\section{SUMMARY}

We found that a change in EOL status following RRT-led EOL discussions was associated with reduced ICU transfers and enhanced access to palliative services. Our study suggested that there is a need to enhance predeterioration EOL planning. Moreover, there is a need to develop institutional support for EOL care, clinician training on EOL care and enhanced access to palliative care services. Future areas of study are to identify patients who will benefit from EOL discussion and to identify the barriers to engaging these patients in EOL discussion.

ACKNOWLEDGEMENTS: BT contributed to research design, data acquisition, statistical analysis, data interpretation and wrote the manuscript. MS contributed to data acquisition. AFR contributed to research design, data interpretation, revising the manuscript and approved the final submission. The authors thank Ms Eley Wisniewski who provided the initial database abstraction.

DISCLOSURES: The authors have no financial disclosures or conflicts of interest to declare.

13. Tolle SW, Tilden VP, Nelson CA, Dunn PM. A prospective study of the efficacy of the physician order form for life-sustaining treatment. J Am Geriatr Soc 1998;46:1097-102.

14. Bomba PA, Kemp M, Black JS. POLST: An improvement over traditional advance directives. Clev Clin J Med 2012;79:457-64.

15. Schmidt TA, Olszewski EA, Zive D, et al. The Oregon physician orders for life-sustaining treatment registry: A preliminary study of emergency medical services utilization. J Emerg Med 2013;44:786-805.

16. Curtis JR, Vincent J-L. Critical care: Ethics and end-of-life care for adults in the intensive care unit. Lancet 2010;376:1347-53.

17. Smith RL, Hayashi VN, Lee YI, Navarro-Mariazeta L, Felner K. The medical emergency team call. Crit Care Med 2013;42:322-7.

18. Jones DA, Bagshaw SM, Barrett J, et al. The role of the medical emergency team in end-of-life care. Crit Care Med 2012;40:98-103.

19. Kause J, Smith G, Prytherch D, Parr M, Flabouris A, Hillman K. A comparison of Antecedents to Cardiac Arrests, Deaths and EMergency Intensive care Admissions in Australia and New Zealand, and the United Kingdom - the ACADEMIA study. Resuscitation 2004;62:275-82.

20. Heyland DK. Failure to engage hospitalized elderly patients and their families in advance care planning between patient and families. JAMA Intern Med 2013;173:778-87.

21. Nelson J, Angus D, Weissfeld L, et al. End of life care for the critcally ill: A national intensive care unit survey. Crit Care Med 2006;34:3071.

22. Festic E, Wilson ME, Gajic O, Divertie GD, Rabatin JT. Perspectives of physicians and nurses regarding end-of-life care in the intensive care unit. J Intens Care Med 2012;27:45-54.

23. Cooper Z, Meyers M, Keating NL, Gu X, Lipsitz SR, Rogers SO. Resident education and management of end-of-life care: The resident's perspective. J Surg 2011;67:79-84.

24. Gorman T, Ahern S, Wiseman J, Skrobik Y. Residents' end-of-life decision making with adult hospitalized patients: A review of the literature. Acad Med 2005;80:1-12.

25. Curtis JR, Nielsen EL, Treece PD, et al. Effect of a qualityimprovement intervention on end-of-life care in the intensive care unit. Am J Respir Crit Care Med 2011;183:348-55. 
26. O'Mahony S, McHenry J, Blank AE, et al. Preliminary report of the integration of a palliative care team into an intensive care unit. Palliat Med 2010;24:154-65.

27. Heyland DK. What matters most in end-of-life care: Perceptions of seriously ill patients and their family members. CMAJ 2006;174:627-33.

28. De Roo ML, Leemans K, Claessen SJ, et al. Quality indicators for palliative care: Update of a systematic review. J Pain Symptom Manage 2013;46:556-72.

29. Bouley G. The rapid response team nurse's role in end-of-life discussions during critical situations. Dimens Crit Care Nurs 2011;30:321-5.

30. Aslakson R, Pronovost PJ. Health care quality in end-of-life care: Promoting palliative care in the intensive care unit. Anesthesiol Clin 2011;29:111-22.

31. Adams JA, Bailey DE, Anderson RA, Docherty SL. Nursing roles and strategies in end-of-life decision making in acute care: A systematic review of the literature. Nurs Res Pract 2011;2011:1-15.
32. Clarke EB, Curtis JR, Luce JM, et al. Quality indicators for end-oflife care in the intensive care unit. Critical Care Med 2003;31:2255-62.

33. Hohenleitner R. Critical care nurses' role in code status discussion. Dimen Crit Care Nurs 2002;21:1-4.

34. Randall Curtis J, Patrick D, Shannon SE, Treece PD, Engelberg RA, Rubenfeld GD. The family conference as a focus to improve communication about end-of-life care in the intensive care unit: Opportunities for improvement. Crit Care Med 2001;29:1-8.

35. Coventry C, Flabouris A, Sundararajan K, Cramey T; European Resuscitation Council, American Heart Association Inc, and International Liaison Committee on Resuscitation. Elsevier Ireland Ltd; 2013;84:1035-9. 


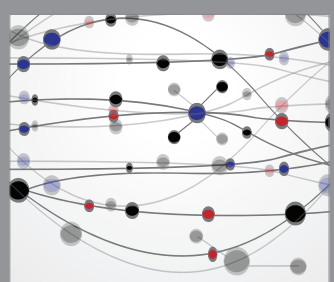

The Scientific World Journal
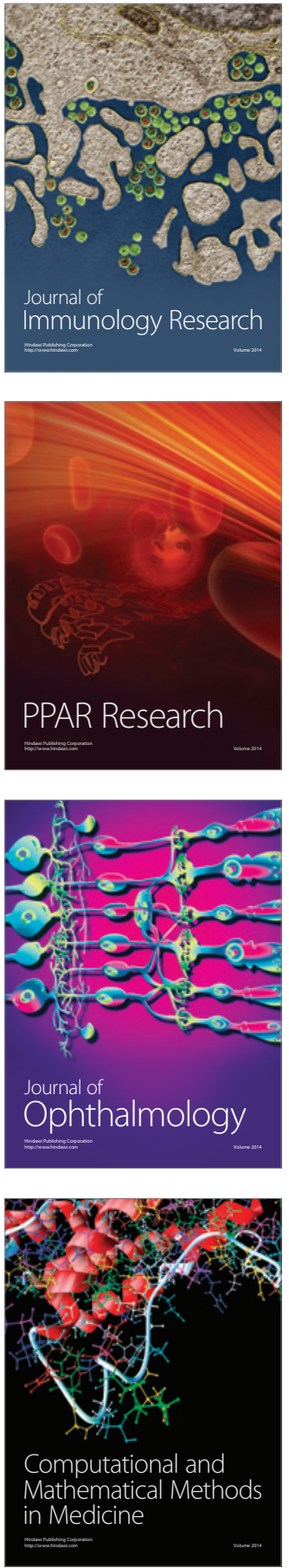

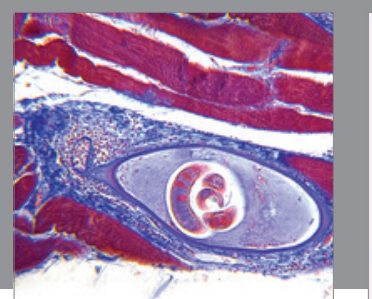

Gastroenterology Research and Practice

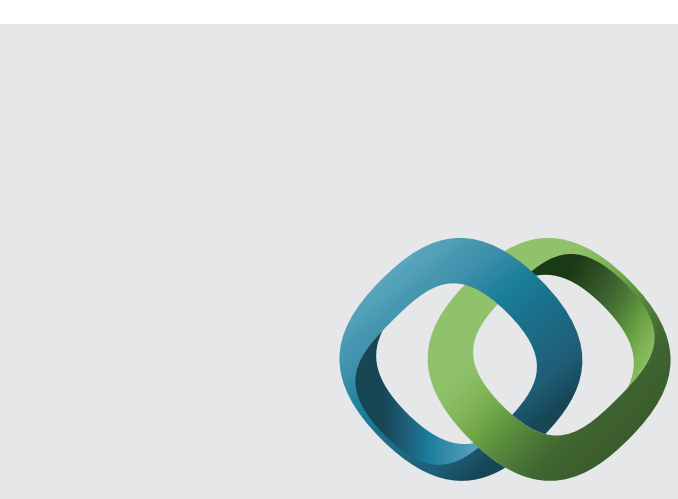

\section{Hindawi}

Submit your manuscripts at

http://www.hindawi.com
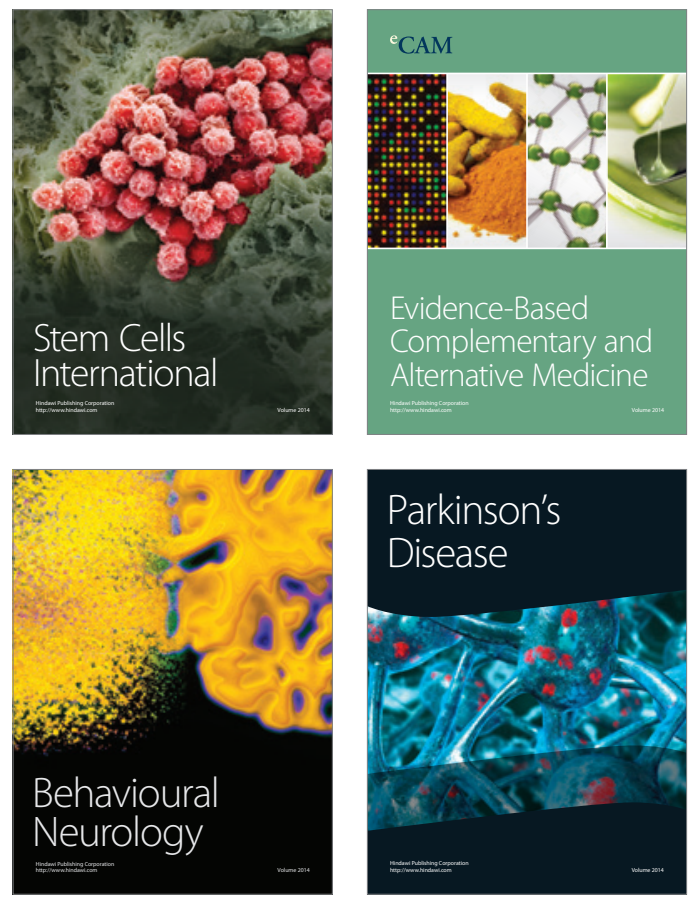
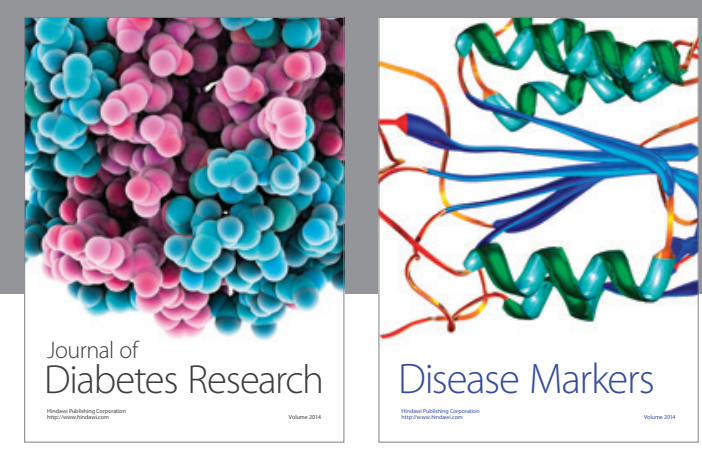

Disease Markers
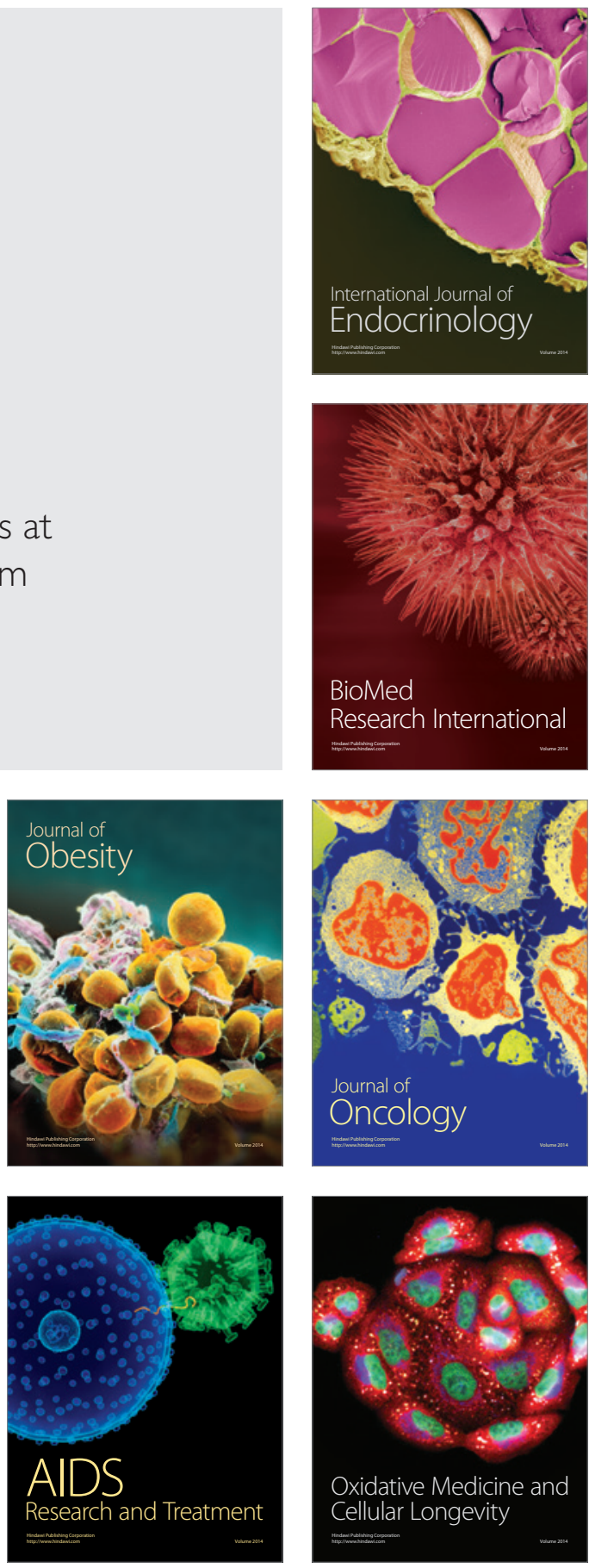